\title{
Altered ivermectin pharmacology and defective visual system in Drosophila mutants for histamine receptor HCLB
}

\author{
Shazie Yusein · Nadya Velikova · Petia Kupenova · \\ Roger Hardie · Adrian Wolstenholme · \\ Eugene Semenov
}

Published online: 21 November 2008

(C) Springer-Verlag 2008

\section{Erratum to: Invert Neurosci}

\section{DOI 10.1007/s10158-008-0078-2}

The original version of this article unfortunately contained a mistake. The presentation of Fig. 6 was published with an error. The correct version is given on the next page.

The online version of the original article can be found under doi:10.1007/s10158-008-0078-2.

S. Yusein · N. Velikova · P. Kupenova · E. Semenov $(\bowtie)$

Department of Molecular Neurobiology,

Institute of Molecular Biology, 1113 Sofia, Bulgaria

e-mail: esen@obzor.bio21.bas.bg

R. Hardie

Department of Physiology, Development and Neuroscience, Cambridge University, Cambridge CB2 3DY, UK

A. Wolstenholme

Department of Biology and Biochemistry, University of Bath,

Claverton Down, Bath BA2 7AY, UK 
Fig. 6 Allele-specific changes of the transient components of the ERGs following ivermectin application. The number of responses registered under specific experimental conditions for a given experimental group of 10 animals is shown in Table 3. a, d and g $O R / D f(3 R) E 79 ; \mathbf{b}$, e and h $h c l B^{T 1} / D f(3 R) E 79 ; \mathbf{c}, \mathbf{f}$ and i $h c l B^{T 2} / D f(3 R) E 79$

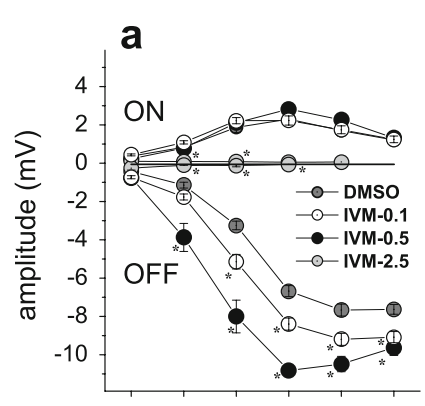

b
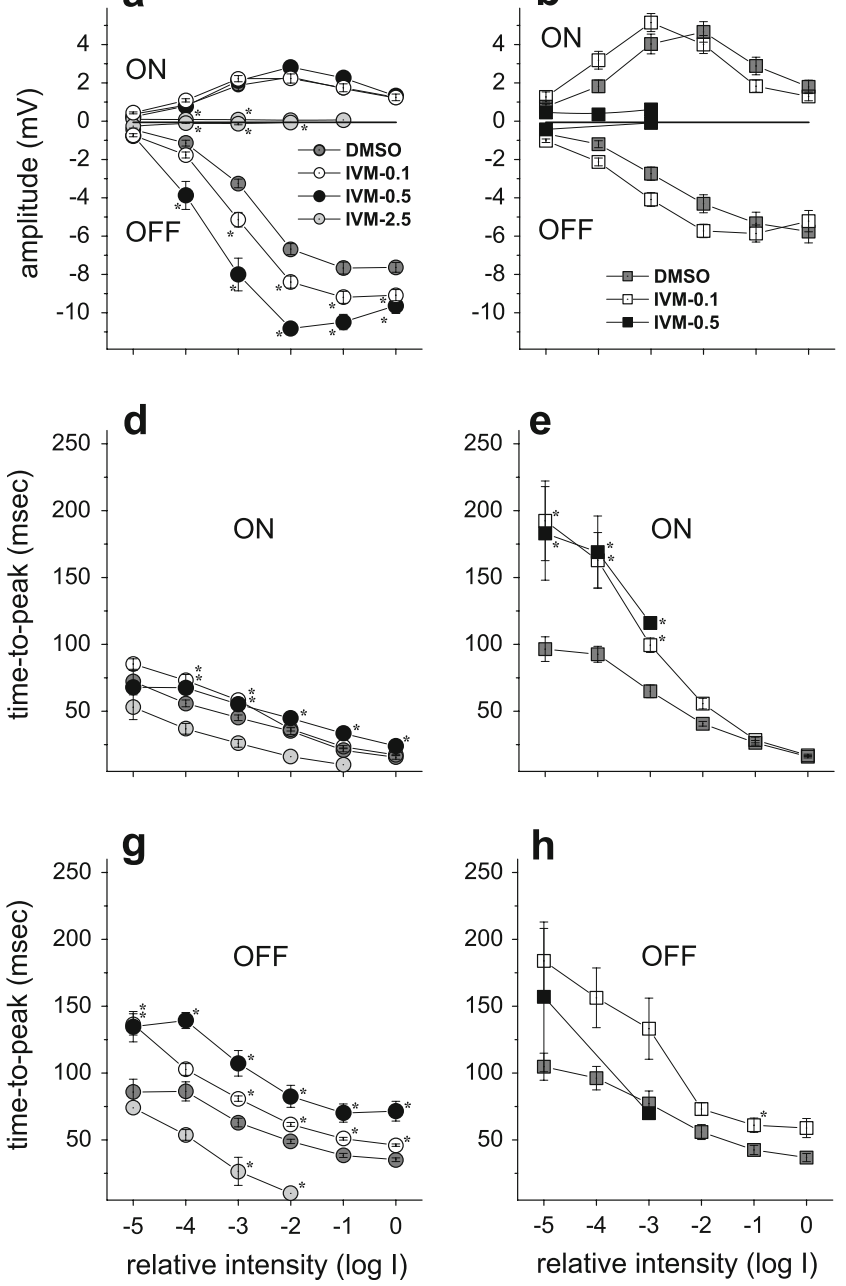
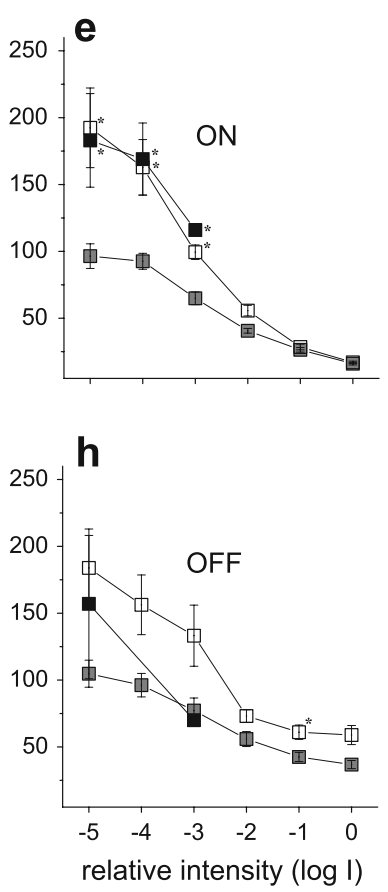
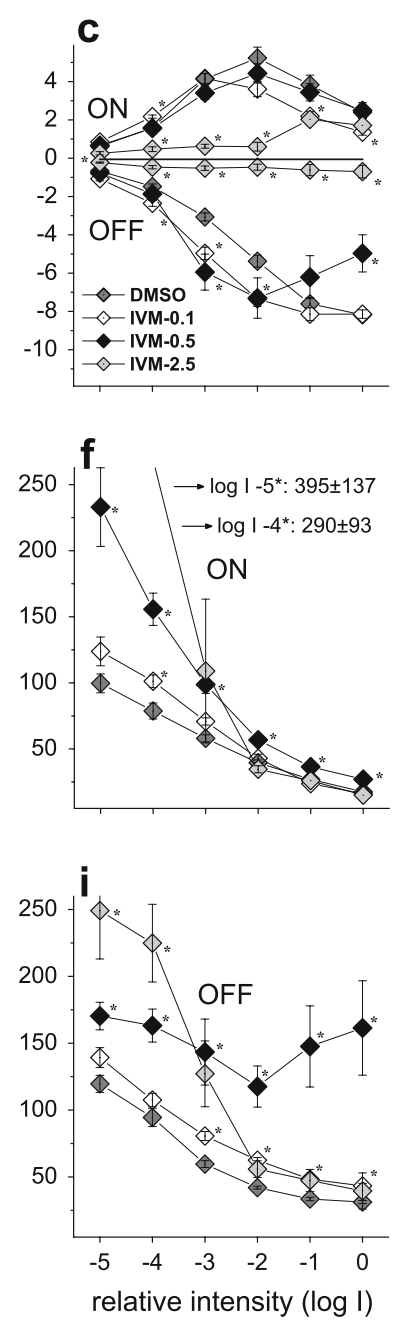